\title{
1. Allopatric origin of sympatric whitefish morphs with insights on the genetic basis of their reproductive isolation
}

Bohao Fang ${ }^{1,2}$, Paolo Momigliano ${ }^{1,3}$, Kimmo K. Kahilainen ${ }^{4,5} \&$ Juha Merilä ${ }^{1,3}$

\author{
1. Ecological Genetics Research Unit, Organismal and Evolutionary Biology Research Programme, Faculty of Biological \\ and Environmental Sciences, University of Helsinki, Helsinki, Finland \\ 2. Department of Organismic and Evolutionary Biology and Museum of Comparative Zoology, Harvard University, 26 \\ Oxford Street, Cambridge, MA, USA. \\ 3. Research Division for Ecology and Biodiversity, The School of Biological Sciences, The University of Hong Kong, \\ Hong Kong SAR \\ 4. Lammi Biological Station, University of Helsinki, Pääjärventie 320, 16900 Lammi, Finland \\ 5, Kilpisjärvi Biological Station, University of Helsinki, Käsivarrentie 14622, 99490 Kilpisjärvi, Finland
}

\section{Abstract}

The European whitefish (Coregonus lavaretus) species complex is a classic example of recent adaptive radiation. Here we examine a whitefish population introduced to northern Finnish Lake Tsahkal in late 1960's, where three divergent morphs (viz. littoral, pelagic and profundal feeders) were found ten generations after. Using demographic modelling based on genomic data we show that whitefish morphs evolved during a phase of strict isolation, refuting a rapid symmetric speciation scenario. The lake is now an artificial hybrid zone between morphs originated in allopatry. Despite their current syntopy, clear genetic differentiation remains between two of the three morphs. Using admixture mapping three quantitative trait loci associated with gonad weight variation, a proxy for sexual maturity and spawning time, were identified. We suggest that ecological adaptations in spawning time evolved in allopatry are currently maintaining partial reproductive isolation in the absence of other barriers to gene flow.

\section{Keywords}

Coregonus lavaretus, whitefish, admixture mapping, gonad weight, demographic modelling

\section{Running title}

Ecological genomics of sympatric whitefish morphs

Correspondence to BF (bohao.fang@helsinki.fi) 


\section{Introduction}

The pace at which evolution and speciation occur, and the mechanisms determining their tempo, have intrigued evolutionary biologists for a long time ((Simpson 1944; Bush et al. 1977; Kornfield 1978)), and still continue today (Schluter 2000; Nosil 2012; Lescak et al. 2015; Momigliano et al. 2017; Salzburger 2018; Skúlason et al. 2019). Concerns over the organims' ability to adapt to environmental changes (e.g. Gienapp et al. (2008); Merilä \& Hendry (2014)), and the realisation that adaptation can be very rapid (Thomas et al. 2017; Matthews et al. 2018; Marques et al. 2019b), have sparked new interest towards the rates of evolution. Adaptation from standing genetic variation can be fast, especially if genetic diversity has been augmented by historical gene flow (Häkli et al. 2018; Salzburger 2018; Jacobs et al. 2019; Marques et al. 2019a). One example is the evolution of freshwater-adapted three-spined sticklebacks (Gasterosteus aculeatus) colonising ponds that were formed during uplift caused by the 1964 Great Alaska Earthquake (Lescak et al. 2015). Similarly rapid adaptation has been observed for sockeye salmon and Darwin's finches when colonizing new environments (Hendry et al. 2000; Lamichhaney et al. 2018). In all these examples, broad ecological opportunities likely facilitated rapid phenotypic and genetic differentiation.

Coregonid fishes have undergone extensive recent adaptive radiations but intermittent gene flow among morphs and species is common (Østbye et al. 2005; Bernatchez et al. 2010; Hudson et al. 2011; Vonlanthen et al. 2012). European whitefish (Coregonus lavaretus) experienced frequent adaptive radiations throughout their distribution (Svärdson 1979; Østbye et al. 2005; Vonlanthen et al. 2012). Facing different ecological opportunities, C. lavaretus evolved partially reproductively isolated, co-existing morphs utilizing different niches (Kahilainen \& Østbye 2006; Siwertsson et al. 2010; Præbel et al. 2013). These morphs differ in several phenotypic traits (Harrod et al. 2010; Præbel et al. 2013), such as body size and number of gill rakers, a heritable traits related to feeding ecology (Kahilainen et al. 2011; Häkli et al. 2018). While rapid whitefish differentiation has been documented in both Nearctic and Palearctic regions (Bernatchez et al. 2010; Hudson et al. 2011), less is known about the genomic basis of their rapid phenotypic divergence (but see Vonlanthen et al. (2012); Jacobs et al. (2019); Rougeux et al. (2019a)).

In northern Finland, the Finnish Fisheries authorities facilitated introductions of whitefish in several high-altitude lakes including Lake Tsahkal, where the species did not previously occur, in 1960's. Sampling in Lake Tsahkal in 2011 revealed three different morphs inhabiting littoral, pelagic and profundal habitats (Kahilainen et al. 2011; Præbel et al. 2013). There is evidence of both allopatric and sympatric speciation of whitefish morphs (Præbel et al. 2013), and genetic diversity fuelled by 
historical admixture can facilitate rapid phenotypic divergence when ecological opportunity arises (Jacobs et al. 2019). It is possible that the whitefish introduced to Lake Tsahkal came from a single ancestral population and gave rise to different morphs in ca. 50 years $(\approx 10$ generations). The alternative hypothesis is that the three morphs were simultaneously introduced in the lake. In such case, the whitefish of Lake Tsahkal would provide a unique opportunity to study the ecological and genetic bases of reproductive barriers following secondary contact.

Lake Tsahkal provides also an ideal system to study the genetic basis of phenotypic traits defining the whitefish morphs via admixture mapping (Gompert et al. 2017). To date, few studies have provided insights on the genetic basis of whitefish phenotypic traits (Vonlanthen et al. 2009; Gagnaire et al. 2013a; Gagnaire et al. 2013b; Feulner \& Seehausen 2019; Jacobs et al. 2019). These studies focus mainly on trophic traits, whereas less attention has been paid on traits associated with timing of reproduction. Timing of reproduction can act as a reproductive barrier among diverging populations (Hendry \& Day 2005), and it is well-known that whitefish morphs have differences in their spawning time and location (e.g. Svärdson (1979); Vonlanthen et al. (2009); Kahilainen et al. (2014); Bitz-Thorsen et al. (2020)).

Here, using a demographic modelling framework, we test two possible divergence scenarios of the Lake Tsahkal whitefish morphs: sympatric speciation and allopatric speciation followed by secondary contact. Furthermore, we investigate the genetic architecture of gonad weight variation, a proxy for spawning time which is a trait expected to be under ecological selection that could lead to reproductive isolation.

\section{Methods}

\section{Study system and data collection}

Lake Tsahkal is located in the treeline of northern Finnish Lapland $\left(69^{\circ} 01^{\prime} \mathrm{N}, 20^{\circ} 50^{\prime} \mathrm{E}, 559 \mathrm{~m}\right.$ a.s.l). The lake is oligotrophic (totP $5 \mu \mathrm{g} / \mathrm{L}$, totN $140 \mu \mathrm{g} / \mathrm{L}$ ), deep (max $35 \mathrm{~m}$, mean $9 \mathrm{~m}$ ), clearwater (compensation depth $7.5 \mathrm{~m}$ ) and has equal habitat distribution (41\% pelagic/profundal, 59\% littoral; Hayden et al. (2014)). Introduced whitefish in the 1960's had broad ecological opportunity, as they are more efficient in zooplanktivory and benthivory than native brown trouts (Salmo trutta) and burbots (Lota lota) (Siwertsson et al. 2010; Hayden et al. 2014). Reproductive isolation among whitefish morphs could arise via differences in resource use causing differences in spawning times and places (Kahilainen et al. 2014; Taylor \& Friesen 2017; Thibert-Plante et al. 2020). 
Littoral, pelagic and profundal zones were identified in the lake (Hayden et al. 2014) (Fig. 1a) and subsequently whitefish were collected from these habitats with gill net series in August 2011 (Kahilainen et al. 2011). Caught fish were transported to field laboratory, labelled and frozen ($20^{\circ} \mathrm{C}$ ) for later measurements of fish size, gill raker count, resource use metrics and morphological traits (for details, see Table S1, Figure S2, S4; Method S1). All caught fish were assigned to three different morphs according to their gill raker appearance, head and body shape (Method S1; Kahilainen \& Østbye (2006)).

A total of 61 individuals (17 littoral, 22 pelagic and 22 profundal fish) were sequenced using $2 b-$ RAD sequencing approach (Wang et al. 2012) to obtain 36 bp single-end fragments with a mean coverage 30.2X (13.7-44.0; electronic supplementary material, Table S1) by Illumina HiSeq 4000 at BGI, Hong Kong. DNA extraction and 2b-RAD library preparation followed exactly the protocols detailed in Momigliano et al. $(2018,2021)$.

\section{Population genetic analyses}

Raw reads were demultiplexed and PCR duplicates removed as per Momigliano et al. (2018). Reads were aligned to a chromosome-level assembly of the alpine European whitefish (Coregonus spp.) publicly available at https://www.ebi.ac.uk/ena/data/view/GCA_9021750, using Bowtie2 (Langmead \& Salzberg 2012). SAM files were converted to BAM files and indexed using SAMtools (Li \& Durbin 2009).

Genotype likelihoods were estimated from BAM files using ANGSD (Korneliussen et al. 2014), retaining only biallelic loci with $\leq 25 \%$ missing data and bases with mapping quality and Phred scores $>20$. We performed a principal component analysis (PCA) using PCAngsd (Meisner \& Albrechtsen 2018) retaining variants with minimum minor allele frequency of 0.02 . Individual ancestries were inferred using NGSadmix (Skotte et al. 2012) based on genotype likelihoods, assuming 1-3 ancestral populations. Absolute divergence $\left(d_{X Y}\right)($ Nei 1987) and net nucleotide divergence ( $D_{a}$, Nei (1987)) were estimated based on non-admixed individuals identified by NGSadmix using scripts from Momigliano et al. (2021).

\section{Demographic modelling}

We compared demographic models using the software package moments (Jouganous et al. 2017) based on diffusion approximations of the allele frequency spectrum (SFS). Ten demographic models were tested using non-admixed littoral and pelagic individuals, as the ancestral pelagic and profundal morphs were not genetically distinct (see Results) and we had more pelagic $(n=8)$ than 
profundal $(\mathrm{n}=5)$ non-admixed individuals. We firstly defined five competing gene flow scenarios: strict isolation (SI), isolation with migration (IM), secondary contact (SC), ancient migration (AM) and a two epochs model (2EP) assuming heterogeneous migration rates through time (Roux et al. 2016; Momigliano et al. 2021). Since unaccounted changes in $N_{e}$ can bias model choice and parameter estimation (Momigliano et al. 2021), we defined five additional models accounting for a change in $N_{e}$ in both daughter populations at time $\mathrm{T}_{2}$, based on the above simple models: SI_NeC, AM_NeC, IM_NeC, SC_NeC and 2EP_NeC; $\mathrm{NeC}$ stands for " $N_{e}$ Change". The 10 tested models are visualized in electronic supplementary material, Figure S3. To account for possible effects of linkage in the 2b-RAD data, the best fitting model was chosen using Likelihood Ratio Test (LRT) as outlined in (Coffman et al. 2016).

All analyses were performed based on the unfolded two-dimensional SFS (2D-SFS) derived from the sites shared between pairwise morphs. The programs ANGSD and Moments, and custom $\mathrm{R}$ and python scripts adopted from Momigliano et al. (2021) and Fang et al. (2021) were used in the analyses. Detailed methods are given in the supplementary material, method S1.

\section{Admixture mapping}

Admixture mapping of phenotypic traits was performed with two genome-wide association (GWA) approaches: GEMMA v.0.98, a genome-wide efficient mixed model association approach (Zhou \& Stephens 2014), and LDna-EMMAX, a linkage disequilibrium (LD) clustering-based approach for association mapping (Kang et al. 2010; Kemppainen et al. 2015; Li et al. 2018; Fang et al. 2021). Univariate linear mixed models were conducted for each phenotypic trait in GEMMA, accounting for relatedness between individuals by supplying relatedness matrix as a covariate. In LDnaEMMAX, we used LD network analyses (LDna, Kemppainen et al. (2015)) to identify correlated clusters of single nucleotide polymorphisms (SNPs), followed by GWA by fitting a multilocus mixed model accounting for relatedness as in Li et al. (2018)) and in Fang et al. (2021). Significance tests of the two GWA approaches were performed based on Wald and permutation tests, respectively. Details and pipelines used perform GWAs are provided in the electronic supplementary material, method S1.

\section{Results}

(a) Population structure and demographic history 
Littoral and pelagic morphs differed significantly in body size, gill raker count, morphology, diet and parasites, whereas profundal morph was intermediate (electronic supplementary material, Figure S4). Stable isotopes and mercury indicated clear differentiation of all three whitefish morphs in their respective habitats (electronic supplementary material, Figure S4). We obtained genotype likelihoods of 15,615 loci across 61 whitefish individuals. NGSadmix analyses revealed two ancestral components $(\mathrm{K}=2)$, and a clear genetic differentiation between littoral and pelagic/profundal morphs in analysis of non-admixed individuals (Fig. 1b-d). Overall divergence between non-admixed pelagic and profundal morphs was low: $d_{X Y}=1.14 \mathrm{e}-3$ (95\%CI: $1.08 \mathrm{e}-3-1.21 \mathrm{e}-$ 3; Fig. 1b) and $D_{a}=1.81 \mathrm{e}-6$ (95\%CI: -1.37e-5-1.56e-5; Fig. 1c). Out of 61 individuals analysed, 41 were genetically admixed (i.e., having $>3 \%$ ancestry from a different cluster; Fig. 1d). PCA support these inferences, showing no differentiation of pelagic and profundal morphs, and admixture between littoral and pelagic morphs (Fig. 1e).

The demographic analyses identified secondary contact with changes in $N_{e}$ (SC_NeC; Fig. 1f; electronic supplementary material, Figure S5, S6) as the best-fit model. Littoral and pelagic morphs diverged 296.15 thousand years ago (kya; 95\% CI: 284.46-307.84 kya, i.e., 56.89-61.57 thousand generations), and experienced a secondary contact following the end of the last glaciation 19.9 kya (95\% CI: 17.44-22.51 kya, 3.49-4.50 thousand generations) with decreases in $N_{e}$ for both morphs after the Last Glacial Maximum (LGM; Fig. 1f). For a summary of scaled parameters, see the electronic supplementary material, Table S2.

\section{(b) Admixture mapping}

Both GWA analyses revealed three SNPs (Chromosome [Chr] 22: 43,111,579, Chr 28: 9, 855, 214 and $C h r$ 36: 8,058,628) associated with gonad weight variation in the 41 admixed individuals when treating age of individuals as a covariate in the models (Fig. 2a-c). The genotypes of the three SNPs explained $67.35 \%$ of the variation in gonad weight $\left(R^{2}=0.67\right.$; Fig. $\left.2 \mathrm{c}\right)$. When using the body weight as a covariate, two of the three SNPs (Chr 22: 43,111,579 and Chr 36: 8,058,628) were identified significantly associated with the gonad weight in the GEMMA, while not in LDna-EMMAX (electronic supplementary material, Fig. S8). However, these two SNPs are in strong LD $\left(r^{2}>0.9\right)$ and clustered in LDna (the first step in LDna-EMMAX analyses). No variant was significantly associated with any of the 22 other traits used to define the morphs (electronic supplementary material, Table S1). 
bioRxiv preprint doi: https://doi.org/10.1101/2021.09.11.459905; this version posted September 12, 2021. The copyright holder for this preprint (which was not certified by peer review) is the author/funder, who has granted bioRxiv a license to display the preprint in perpetuity. It is made available under aCC-BY-NC 4.0 International license.

Using demographic models, we refuted the hypothesis of rapid sympatric speciation of whitefish in Lake Tsahkal. Demographic analyses support an allopatric origin of whitefish morphs clearly predating the transplantation to the lake 50 years before sampling. This is not entirely surprising. While there are examples of rapid adaptive responses to novel environmental conditions on similar timescales (e.g. Bell et al. (2004); Lescak et al. (2015); Marques et al. (2019b)), in most cases these responses are subtle or have taken place over much longer time (Bolnick \& Fitzpatrick 2007). For instance, the origins of most adaptive radiations in fishes can be traced back over hundreds of thousands years ago (e.g., Albertson et al. (1999); Danley \& Kocher (2001); Hudson et al. (2007); Hudson et al. (2011); but see: Lescak et al. (2015); Jacobs et al. (2019).

Our results suggest that following a long phase of strict isolation, gene flow between divergent whitefish morphs was re-established during the last glacial retreat. Similar cases of secondary contact in post-glacial lakes have been reported from other northern temperate zone whitefish and they often led to hybridization (Bernatchez et al. 2010; Hudson et al. 2011; Rougeux et al. 2017; Rougeux et al. 2019b). The observed gradient of admixture suggests that the introduction of whitefish to the Lake Tsahkal created an artificial hybrid zone facilitating gene flow between littoral and pelagic morphs. The absence of genetic differentiation between the pelagic and profundal morphs was somewhat surprising. It is possible that these phenotypic differences are driven by plasticity but given our relatively low coverage of the whitefish genome it is also possible that we have missed important genetic differences between the two morphs.

An important finding from this study is the identification of three SNPs associated with gonad weight variation. Gonad weight is an interesting trait because of its association with spawning time and thereby also with reproductive isolation among whitefish morphs. It is known that whitefish morphs have different spawning times, habitats and size at maturity (Svärdson 1979; Vonlanthen et al. 2009; Bitz-Thorsen et al. 2020). The fact that the relative size of the gonads was largest in the littoral morph and smallest in the profundal morph makes perfectly sense as the former is an earlier breeder than the latter (Kahilainen et al. 2014). That differences in relative size of the gonads among the morphs were further mirrored in corresponding differences in frequency of three SNPs associated with gonad size strongly suggest that these SNPs are associated with breeding time differences among the morphs. Further weight on this inference is provided by the fact that in the lake whitefish (C. clupeaformis) gonadosomatic index maps to chromosome 28 similarly to one of the SNPs identified by us (Gagnaire et al. 2013a). Furthermore, two of the SNPs associated with gonad weight variation displayed strong long-range $\operatorname{LD}\left(r^{2}>0.9\right)$ across chromosomes $(C h r .22$ and 
36), a pattern that could be indicative of strong selection (Lewontin \& Kojima 1960; Nei \& Li 1973). Ecological based selection for different spawning times may generate strong reproductive barriers and maintain reproductive isolation in syntopy as suggested by simulation models (ThibertPlante et al. 2020) and empirical studies on European and Baltic flounders (Momigliano et al. 2017; Momigliano et al. 2018), the Atlantic cod (Fevolden \& Pogson 1997; Hemmer-Hansen et al. 2013; Berg et al. 2016).

We found no SNP associated with gill raker number variation, a highly heritable trait playing a central role in adaptive radiations of coregonids (Bernatchez 2004; Rogers \& Bernatchez 2007; Kahilainen et al. 2011). This is possibly a result of the small sample size of 41 admixed individuals and limited number of markers, which lowers the statistical power of GWA analyses (Hong \& Park 2012). This could be particularly important if variation in gill raker number is a polygenic trait, which are notoriously difficult to map using GWA.

In conclusion, we provide strong evidence that the divergence of the littoral and pelagic morphs in Lake Tsahkal predates their introduction to the lake. While reproductive isolation among the two morphs is incomplete, their genetic differentiation suggests that spawning time differences have likely evolved in allopatry and the morphs are currently maintaining reproductive isolation in the absence of other clear barriers to gene flow. The identification of three SNPs associated with gonad weight variation, a proxy for spawning time, lends support to this hypothesis and provides a starting point to identify causal loci underlying reproductive isolation.

\section{Data accessibility}

Information about samples used is provided in the supplementary material, Table S1. Raw sequence data has been uploaded to NCBI (PRJNA761129). The bioinformatic scripts used are deposited at Dryad (doi: xxx).

\section{Authors' contributions}

J.M. and P.M. conceive the study; B.F. conducted analyses with contributions from P.M.; B.F., J.M. and P.M. wrote the manuscript; K.K. provided samples, ecomorphological data and constructive comments on manuscript; Visualisation by BF; All authors approved the final version of the manuscript. 


\section{Competing interests}

Authors declare no competing interests.

\section{$244 \quad$ Funding}

The research is supported by the Academy Finland (grants \#129662, \#134728, and \#218343 to JM; \#316294 to PM; \#1140903 to KK), European Regional Development Fund (\#A30205 to KK) and Finnish Cultural Foundation (\# 00211290 to BF).

\section{Acknowledgments}

We thank Tiina Holopainen and Petri Nieminen for their help in field work, Miinastiina Issakainen for help with laboratory work, Petri Kemppainen for advice and technical support in admixture mapping. 
bioRxiv preprint doi: https://doi.org/10.1101/2021.09.11.459905; this version posted September $12,2021$. The copyright holder for this preprint (which was not certified by peer review) is the author/funder, who has granted bioRxiv a license to display the preprint in perpetuity. It is made available under aCC-BY-NC 4.0 International license.

\section{References}

Albertson R, Markert J, Danley P, Kocher T. 1999. Phylogeny of a rapidly evolving clade: the cichlid fishes of Lake Malawi, East Africa. Proceedings of the National Academy of Sciences 96:5107-5110.

Bell MA, Aguirre WE, Buck NJ. 2004. Twelve years of contemporary armor evolution in a threespine stickleback population. Evolution 58:814-824.

Berg PR, Star B, Pampoulie C, Sodeland M, Barth JM, Knutsen H, Jakobsen KS, Jentoft S. 2016. Three chromosomal rearrangements promote genomic divergence between migratory and stationary ecotypes of Atlantic cod. Scientific reports $6: 1-12$.

Bernatchez L. 2004. Ecological theory of adaptive radiation: an empirical assessment from coregonine fishes (Salmoniformes). Evolution illuminated: salmon and their relatives:175-207.

Bernatchez L, Renaut S, Whiteley AR, Derome N, Jeukens J, Landry L, Lu G, Nolte AW, Ostbye K, Rogers SM, et al. 2010. On the origin of species: insights from the ecological genomics of lake whitefish. Philosophical Transactions of the Royal Society of London B Biological Sciences 365:1783-1800.

Bitz-Thorsen J, Häkli K, Bhat S, Præbel K. 2020. Allochrony as a potential driver for reproductive isolation in adaptive radiations of European whitefish ecomorphs. Ecology of Freshwater Fish 29:40-49.

Bolnick DI, Fitzpatrick BM. 2007. Sympatric speciation: Models and empirical evidence. Annual Review of Ecology Evolution and Systematics 38:459-487.

Bush GL, Case S, Wilson A, Patton J. 1977. Rapid speciation and chromosomal evolution in mammals. Proceedings of the National Academy of Sciences 74:3942-3946.

Coffman AJ, Hsieh PH, Gravel S, Gutenkunst RN. 2016. Computationally Efficient Composite Likelihood Statistics for Demographic Inference. Molecular Biology and Evolution 33:591-593.

Danley PD, Kocher TD. 2001. Speciation in rapidly diverging systems: lessons from Lake Malawi. Molecular Ecology 10:1075-1086.

Fang B, Kemppainen P, Momigliano P, Merila J. 2021. Population structure limits parallel evolution in sticklebacks. Molecular Biology and Evolution msab144.

Feulner PGD, Seehausen O. 2019. Genomic insights into the vulnerability of sympatric whitefish species flocks. Molecular Ecology 28:615-629.

Fevolden S-E, Pogson GH. 1997. Genetic divergence at the synaptophysin (Syp I) locus among Norwegian coastal and north - east Arctic populations of Atlantic cod. Journal of Fish Biology 51:895-908.

Gagnaire PA, Normandeau E, Pavey SA, Bernatchez L. 2013a. Mapping phenotypic, expression and transmission ratio distortion QTL using RAD markers in the Lake Whitefish (Coregonus clupeaformis). Molecular Ecology 22:30363048 .

Gagnaire PA, Pavey SA, Normandeau E, Bernatchez L. 2013b. The genetic architecture of reproductive isolation during speciation-with-gene-flow in lake whitefish species pairs assessed by RAD sequencing. Evolution 67:2483-2497.

Gienapp P, Teplitsky C, Alho J, Mills J, Merilä J. 2008. Climate change and evolution: disentangling environmental and genetic responses. Molecular Ecology 17:167-178.

Gompert Z, Mandeville EG, Buerkle CA. 2017. Analysis of Population Genomic Data from Hybrid Zones. Annual Review of Ecology, Evolution, and Systematics 48:207-229.

Häkli K, Ostbye K, Kahilainen KK, Amundsen PA, Praebel K. 2018. Diversifying selection drives parallel evolution of gill raker number and body size along the speciation continuum of European whitefish. Ecol Evol 8:2617-2631. 
bioRxiv preprint doi: https://doi.org/10.1101/2021.09.11.459905; this version posted September $12,2021$. The copyright holder for this preprint (which was not certified by peer review) is the author/funder, who has granted bioRxiv a license to display the preprint in perpetuity. It is made available under aCC-BY-NC 4.0 International license.

Harrod C, Mallela J, Kahilainen KK. 2010. Phenotype - environment correlations in a putative whitefish adaptive radiation. Journal of Animal Ecology 79:1057-1068.

Hayden B, Harrod C, Kahilainen KK. 2014. Lake morphometry and resource polymorphism determine niche segregation between cool - and cold - water - adapted fish. Ecology 95:538-552.

Hemmer-Hansen J, Nielsen EE, Therkildsen NO, Taylor MI, Ogden R, Geffen AJ, Bekkevold D, Helyar S, Pampoulie C, Johansen T. 2013. A genomic island linked to ecotype divergence in A tlantic cod. Molecular Ecology 22:26532667.

Hendry AP, Day T. 2005. Population structure attributable to reproductive time: isolation by time and adaptation by time. Molecular Ecology 14:901-916.

Hendry AP, Wenburg JK, Bentzen P, Volk EC, Quinn TP. 2000. Rapid evolution of reproductive isolation in the wild: evidence from introduced salmon. Science 290:516-518.

Hong EP, Park JW. 2012. Sample size and statistical power calculation in genetic association studies. Genomics \& informatics 10:117.

Hudson AG, Vonlanthen P, Mueller R, Seehausen O. 2007. Review: The geography of speciation and adaptive radiation in coregonines. Biology and Management of Coregonid Fishes 60:111.

Hudson AG, Vonlanthen P, Seehausen O. 2011. Rapid parallel adaptive radiations from a single hybridogenic ancestral population. Proceedings of the Royal Society B: Biological Sciences 278:58-66.

Jacobs A, Carruthers M, Eckmann R, Yohannes E, Adams CE, Behrmann-Godel J, Elmer KR. 2019. Rapid niche expansion by selection on functional genomic variation after ecosystem recovery. Nature Ecology and Evolution 3:7786.

Jouganous J, Long W, Ragsdale AP, Gravel S. 2017. Inferring the Joint Demographic History of Multiple Populations: Beyond the Diffusion Approximation. Genetics 206:1549-1567.

Kahilainen K, Østbye K. 2006. Morphological differentiation and resource polymorphism in three sympatric whitefish Coregonus lavaretus (L.) forms in a subarctic lake. Journal of Fish Biology 68:63-79.

Kahilainen KK, Patterson WP, Sonninen E, Harrod C, Kiljunen M. 2014. Adaptive radiation along a thermal gradient: preliminary results of habitat use and respiration rate divergence among whitefish morphs. PLoS ONE 9:e112085.

Kahilainen KK, Siwertsson A, Gjelland KO, Knudsen R, Bohn T, Amundsen PA. 2011. The role of gill raker number variability in adaptive radiation of coregonid fish. Evolutionary Ecology 25:573-588.

Kang HM, Sul JH, Service SK, Zaitlen NA, Kong S-y, Freimer NB, Sabatti C, Eskin E. 2010. Variance component model to account for sample structure in genome-wide association studies. Nature Genetics 42:348-354.

Kemppainen P, Knight CG, Sarma DK, Hlaing T, Prakash A, Maung Maung YN, Somboon P, Mahanta J, Walton C. 2015. Linkage disequilibrium network analysis (LDna) gives a global view of chromosomal inversions, local adaptation and geographic structure. Molecular Ecology Resources 15:1031-1045.

Korneliussen TS, Albrechtsen A, Nielsen R. 2014. ANGSD: Analysis of next generation sequencing data. BMC Bioinformatics 15:356.

Kornfield I. 1978. Evidence for rapid speciation in African cichlid fishes. Experientia 34:335-336.

Lamichhaney S, Han F, Webster MT, Andersson L, Grant BR, Grant PR. 2018. Rapid hybrid speciation in Darwin's finches. Science 359:224-228.

Langmead B, Salzberg SL. 2012. Fast gapped-read alignment with Bowtie 2. Nature methods 9:357-359. 
bioRxiv preprint doi: https://doi.org/10.1101/2021.09.11.459905; this version posted September 12, 2021. The copyright holder for this preprint (which was not certified by peer review) is the author/funder, who has granted bioRxiv a license to display the preprint in perpetuity. It is made available under aCC-BY-NC 4.0 International license.

Lescak EA, Bassham SL, Catchen J, Gelmond O, Sherbick ML, von Hippel FA, Cresko WA. 2015. Evolution of stickleback in 50 years on earthquake-uplifted islands. Proceedings of the National Academy of Sciences of the United States of America 112:E7204-7212.

Lewontin R, Kojima K-i. 1960. The evolutionary dynamics of complex polymorphisms. Evolution:458-472.

Li H, Durbin R. 2009. Fast and accurate short read alignment with Burrows-Wheeler transform. Bioinformatics 25:1754-1760.

Li Z, Kemppainen P, Rastas P, Merilä J. 2018. Linkage disequilibrium clustering-based approach for association mapping with tightly linked genomewide data. Molecular Ecology Resources 18:809-824.

Marques DA, Lucek K, Sousa VC, Excoffier L, Seehausen O. 2019a. Admixture between old lineages facilitated contemporary ecological speciation in Lake Constance stickleback. Nature Communications 10:4240.

Marques DA, Meier JI, Seehausen O. 2019b. A Combinatorial View on Speciation and Adaptive Radiation. Trends in Ecology \& Evolution 34:531-544.

Matthews B, Best RJ, Feulner PG, Narwani A, Limberger R. 2018. Evolution as an ecosystem process: insights from genomics. Genome 61:298-309.

Meisner J, Albrechtsen A. 2018. Inferring Population Structure and Admixture Proportions in Low-Depth NGS Data. Genetics 210:719-731.

Merilä J, Hendry AP. 2014. Climate change, adaptation, and phenotypic plasticity: the problem and the evidence. Evolutionary applications 7:1-14.

Momigliano P, Denys GPJ, Jokinen H, Merilä J. 2018. Platichthys solemdali sp. nov. (Actinopterygii, Pleuronectiformes): A New Flounder Species From the Baltic Sea. Frontiers in Marine Science 5.

Momigliano P, Florin AB, Merila J. 2021. Biases in demographic modeling affect our understanding of recent divergence. Molecular Biology and Evolution 38:2967-2985.

Momigliano P, Jokinen H, Fraimout A, Florin AB, Norkko A, Merila J. 2017. Extraordinarily rapid speciation in a marine fish. Proceedings of the National Academy of Sciences of the United States of America 114:6074-6079.

Nei M. 1987. Molecular evolutionary genetics: Columbia university press.

Nei M, Li W-H. 1973. Linkage disequilibrium in subdivided populations. Genetics 75:213-219.

Nosil P. 2012. Ecological speciation: Oxford University Press.

Østbye K, Bernatchez L, Naesje T, Himberg KJ, Hindar K. 2005. Evolutionary history of the European whitefish Coregonus lavaretus (L.) species complex as inferred from mtDNA phylogeography and gill - raker numbers. Molecular Ecology 14:4371-4387.

Præbel K, Knudsen R, Siwertsson A, Karhunen M, Kahilainen KK, Ovaskainen O, Ostbye K, Peruzzi S, Fevolden SE, Amundsen PA. 2013. Ecological speciation in postglacial European whitefish: rapid adaptive radiations into the littoral, pelagic, and profundal lake habitats. Ecol Evol 3:4970-4986.

Rogers S, Bernatchez L. 2007. The genetic architecture of ecological speciation and the association with signatures of selection in natural lake whitefish (Coregonus sp. Salmonidae) species pairs. Molecular Biology and Evolution $24: 1423-1438$.

Rougeux C, Bernatchez L, Gagnaire P-A. 2017. Modeling the multiple facets of speciation-with-gene-flow toward inferring the divergence history of lake whitefish species pairs (Coregonus clupeaformis). Genome Biology and Evolution 9:2057-2074. 
bioRxiv preprint doi: https://doi.org/10.1101/2021.09.11.459905; this version posted September 12, 2021. The copyright holder for this preprint (which was not certified by peer review) is the author/funder, who has granted bioRxiv a license to display the preprint in perpetuity. It is made available under aCC-BY-NC 4.0 International license.

Rougeux C, Gagnaire P-A, Praebel K, Seehausen O, Bernatchez L. 2019a. Polygenic selection drives the evolution of convergent transcriptomic landscapes across continents within a Nearctic sister species complex. Molecular Ecology 28:4388-4403.

Rougeux C, Gagnaire PA, Bernatchez L. 2019b. Model-based demographic inference of introgression history in European whitefish species pairs'. Journal of Evolutionary Biology 32:806-817.

Roux C, Fraisse C, Romiguier J, Anciaux Y, Galtier N, Bierne N. 2016. Shedding light on the grey zone of speciation along a continuum of genomic divergence. PLoS Biology 14:e2000234.

Salzburger W. 2018. Understanding explosive diversification through cichlid fish genomics. Nature Reviews Genetics 19:705-717.

Schluter D. 2000. The ecology of adaptive radiation: OUP Oxford.

Simpson GG. 1944. Tempo and mode in evolution: Columbia University Press.

Siwertsson A, Knudsen R, Kahilainen K, Præbel K, Primicerio R, Amundsen P-A. 2010. Sympatric diversification as influenced by ecological opportunity and historical contingency in a young species lineage of whitefish.

Skotte L, Korneliussen TS, Albrechtsen A. 2012. Association testing for next-generation sequencing data using score statistics. Genetic Epidemiology 36:430-437.

Skúlason S, Parsons KJ, Svanbäck R, Räsänen K, Ferguson MM, Adams CE, Amundsen PA, Bartels P, Bean CW, Boughman JW. 2019. A way forward with eco evo devo: an extended theory of resource polymorphism with postglacial fishes as model systems. Biological Reviews 94:1786-1808.

Svärdson G. 1979. Speciation of Scandinavian Coregonus. Report: Institute of Fresh-water Research, Drottningholm:12-95.

Taylor RS, Friesen VL. 2017. The role of allochrony in speciation. Molecular Ecology 26:3330-3342.

Thibert-Plante X, Præbel K, Østbye K, Kahilainen KK, Amundsen P-A, Gavrilets S. 2020. Using mathematical modelling to investigate the adaptive divergence of whitefish in Fennoscandia. Scientific reports 10:1-12.

Thomas SM, Harrod C, Hayden B, Malinen T, Kahilainen KK. 2017. Ecological speciation in a generalist consumer expands the trophic niche of a dominant predator. Scientific Reports 7:8765.

Vonlanthen P, Bittner D, Hudson AG, Young KA, Müller R, Lundsgaard-Hansen B, Roy D, Di Piazza S, Largiadèr CR, Seehausen O. 2012. Eutrophication causes speciation reversal in whitefish adaptive radiations. Nature 482:357-362.

Vonlanthen P, Roy D, Hudson A, Largiadèr CR, Bittner D, Seehausen O. 2009. Divergence along a steep ecological gradient in lake whitefish (Coregonus sp.). Journal of Evolutionary Biology 22:498-514.

Wang S, Meyer E, McKay JK, Matz MV. 2012. 2b-RAD: a simple and flexible method for genome-wide genotyping. Nature methods 9:808-810.

Zhou X, Stephens M. 2014. Efficient multivariate linear mixed model algorithms for genome-wide association studies. Nature Methods 11:407-409. 


\section{Figures}

(a)

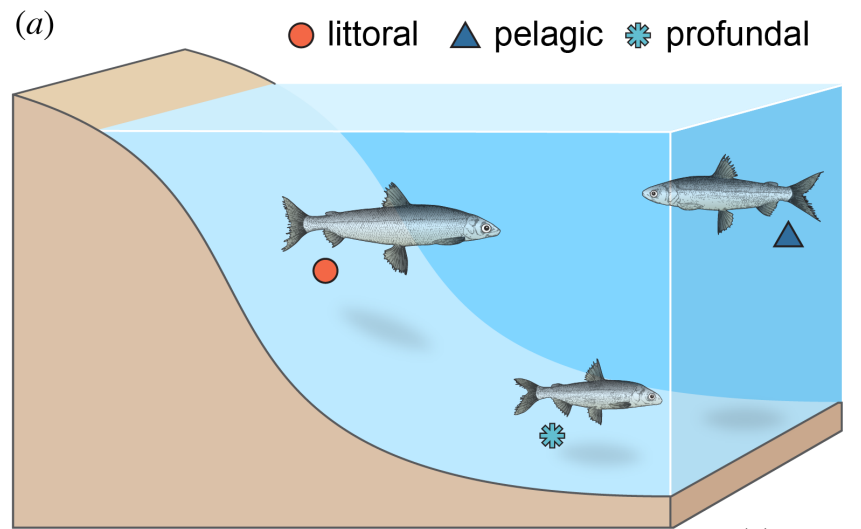

$(d)$

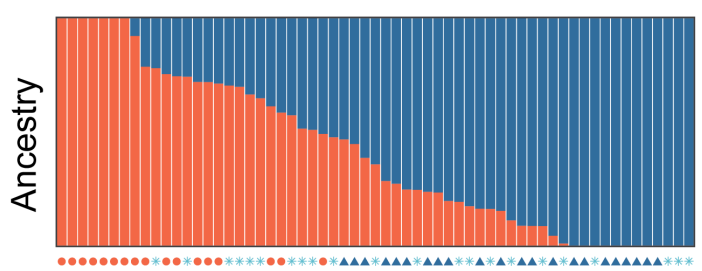
supplementary material, Figure S3.
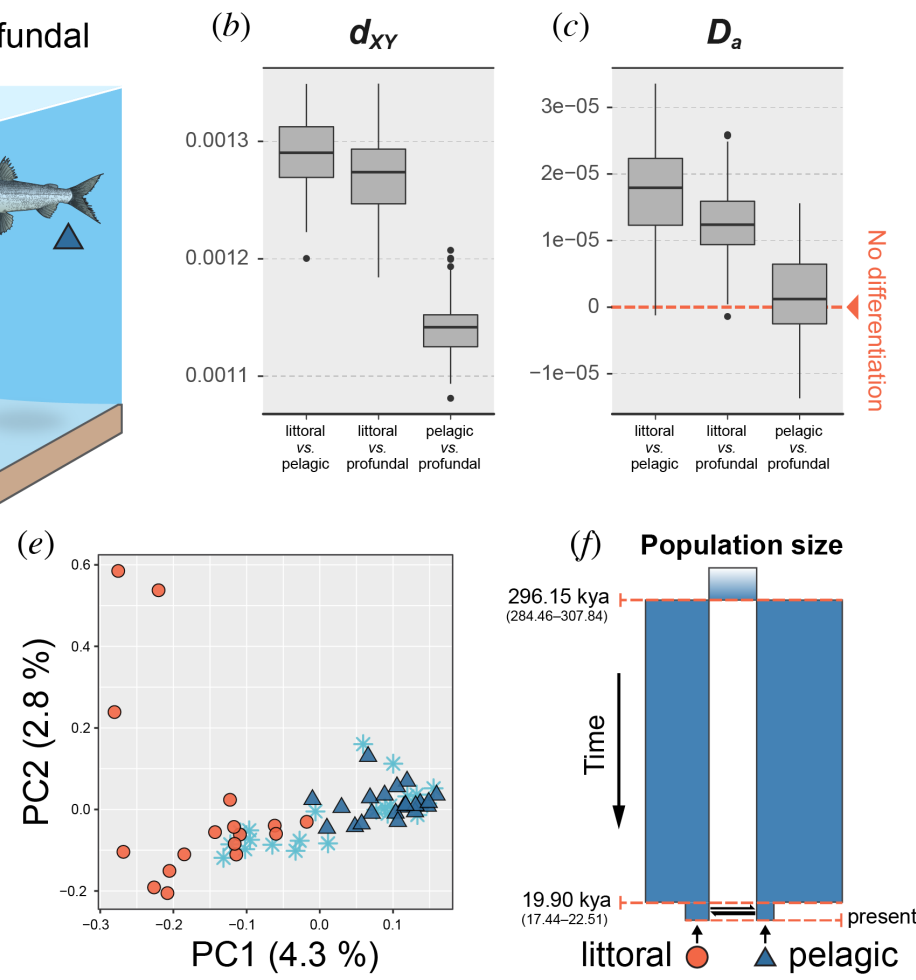

Figure 1. Population structure and demographic history of three morphs of the European whitefish (Coregonus lavaretus) in Lake Tsahkal. (a) Graphic presentation of the littoral, pelagic and profundal morphs inhabiting the lake. $(\mathrm{b}, \mathrm{c})$ Genome-wide divergence (absolute divergence, $d_{X Y}$ and net pairwise nucleotide divergence, $D_{a}$ ) between morphs. Boxplots show 100 bootstraps by permuting sites within chromosome. (d) Individual ancestry reconstructed from NGSadmix at $\mathrm{K}=2$. (e) Principal component analysis (PCA) of genotype likelihoods of 15,615 SNPs. (f) Inferred demographic history of the littoral and pelagic morphs: secondary contact with changes in populations sizes. Estimated time parameters with 95\% confidence intervals are shown. Kya, thousand years ago. Sample identifications of the $(\mathrm{d}, \mathrm{e})$ are presented in the electronic 
$(a)$

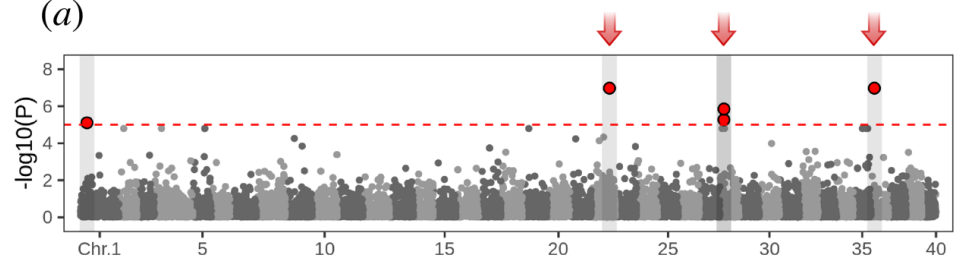

(b)

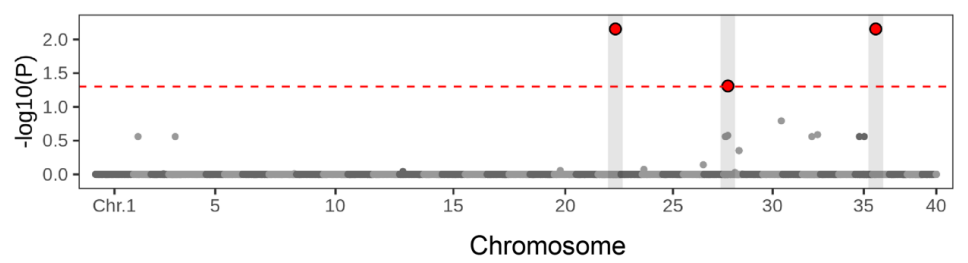

(c)

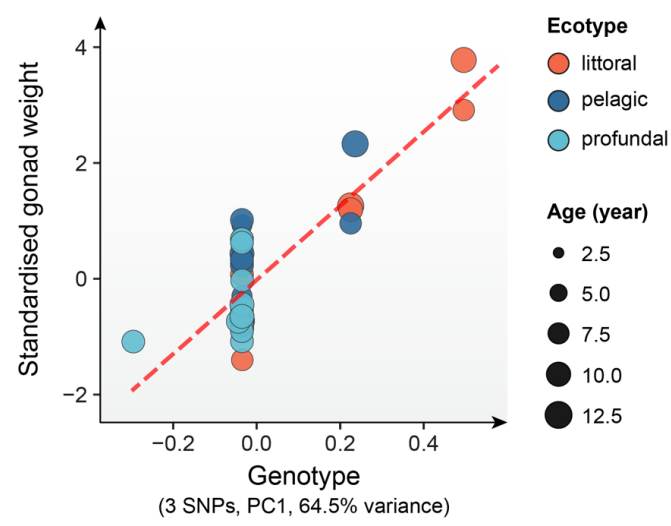

Figure 2. Admixture mapping of the gonad weight variation in European whitefish. Admixture mapping using GEMMA (a) and LDna-EMMAX (b) with age as covariate in models suggested three single-nucleotide polymorphisms (SNPs) significantly associated with the gonad weight variation. In $(a, b, c), x$-axis depicts genomic position and the $y$-axis the negative logarithm of the association $P$-value. Dashed red line marks the significance threshold adjusted for multiple testing. $\mathrm{Chr}=$ chromosome. (d) Correlation between the genotypes of gonad weight-associated SNPs and the standardised gonad weight, the residuals in a linear regression model relating the gonad weight to the body weight of individuals $\left(\mathrm{y}=6.4 \mathrm{x}-0.02 ; R^{2}=0.67 ; P<5.1 \mathrm{e}-11\right)$. 